\title{
An Athlete's Right to Privacy Regarding Sport- RELATED INJURIES: HIPAA AND THE CREATION OF THE MYSTERIOUS INJURY
}

\author{
James Blake Hike*
}

TABLE OF CONTENTS

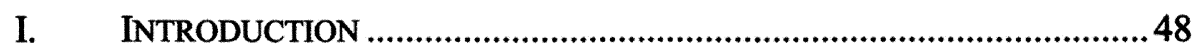

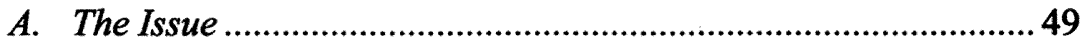

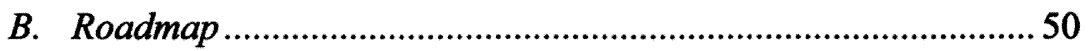

II. HEALTH INFORMATION PORTABILITY AND ACCOUNTABILITY ACT. 51

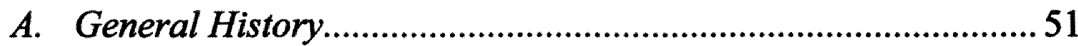

B. Necessary Definitions and Covered Information ........................52

1. Protected Health Information .................................................52

2. What Constitutes a "Covered Entity"? .................................53

a. Intercollegiate athletic community .................................53

b. Professional athletic community .....................................5 54

3. "Minimum Necessary" Disclosure ........................................5 54

4. The Role of Authorization ......................................................55

a. Identification of the party authorizing disclosure ..........56

b. A description of the protected health information authorized for disclosure................................................ 56

c. Identification of the party(s) authorized to make use of the disclosures................................................................... 56

d. Identification of the party(s) authorized to receive the disclosures......................................................................5 57

e. A description of the exact purpose for disclosure ..........57

$f$. A listed date or event causing the authorization to expire............................................................................ 57

g. The date in which the individual signed the

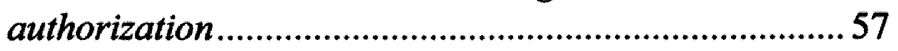

III. INTERESTS AT PLAY .................................................................58

A. The Athlete's Interest in PHI Confidentiality ...............................58

$B$. The Organization's Interest in Running a Business and

Providing Information to the Media and the Public ....................60

1. A Sense of Community .........................................................6 60

2. Taxing the Public to Build a New Stadium or Relocate....... 61

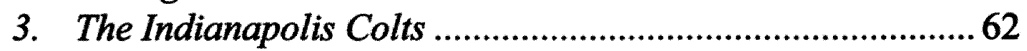

4. The Green Bay Packers ........................................................64

* J.D. Candidate, 2009, Indiana University School of Law_Indianapolis; B.S., 2006, Manchester College. 
C. The Public's Interest in Obtaining Information and Knowledge About Individuals Who Have Placed Themselves in the Public Eye

IV. AN ATTEMPT AT COMPLIANCE: ORGANIZATIONAL MODELS .........67

A. National Basketball Association Collective Bargaining Agreement

B. National Football League Collective Bargaining Agreement.... 68

C. National Collegiate Athletic Association 69

1. Butler University Sports Medicine Standard Authorization Form 69

2. Notice Plus Informed Consent Model .................................70

D. National Athletic Trainers' Association .................................... 70

V. PUBLIC POLICY RATIONALE ......................................................... 71

A. The Promotion of Betting Lines and Gambling ...................... 71

B. Contractual Waiver of Protected Health Information............... 72

1. Non-sports-related Injuries.............................................. 72

2. Sports-related Injuries ..................................................... 73

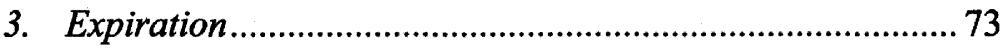

C. Blanket Authorizations............................................................ 74

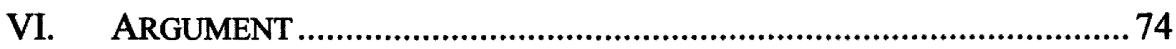

A. Balancing of Interests ......................................................... 75

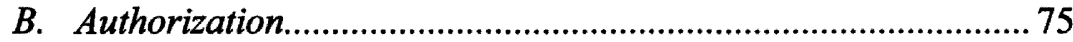

C. Public Policy .......................................................................... 76

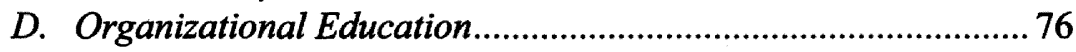

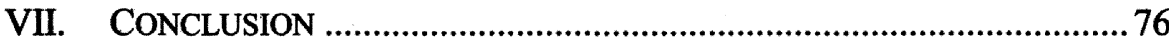

\section{INTRODUCTION}

Coming off of back-to-back seasons in which he compiled over 1700 yards and tallied 17 or more touchdowns, Larry Johnson had high hopes for the 2007-2008 National Football League ("NFL") season. " After spending the Kansas City Chiefs' ("Chiefs") entire training camp negotiating a new contract, however, Johnson began the season with a slight hamstring injury and never seemed to get going. ${ }^{2}$ In a November 4, 2008 game against the Green Bay Packers, Johnson limped off the field, putting no weight on his right leg. ${ }^{3}$ From the moment Johnson left the field, announcers and fans began to speculate. The subsequent actions taken by Johnson and the Chiefs organization led to the creation of a mystery injury.

1. Larry Johnson, http://www.nfl.com/players/larryjohnson/profile?id=JOH399484 [hereinafter Johnson] (last visited Jan. 28, 2009).

2. Randy Covitz, Larry Johnson Frustrated By Way His 2007 Season Played Out, THE KANSAS CITY STAR, Jan. 30, 2008.

3. Jason Whitlock, Chiefs Season Takes Another Strange Twist, THE KANSAS CITY STAR, Nov. 4, 2007. 
After Johnson limped off the field on November 4th, the Chiefs' organization failed initially to issue a formal statement disclosing any specifics about the injury. ${ }^{4}$ Additionally, Johnson neglected to issue a statement as to the exact nature of his condition, noting only the severity of the initial swelling and the fact that the condition improved to where he could walk without a protective boot. ${ }^{5}$ It is important to note that NFL organizations typically release information relating to on-field injuries. ${ }^{6}$ When the Chiefs' president, Carl Peterson, finally issued a formal statement, the information he provided remained ambiguous. Peterson stated, “[i]f a patient doesn't want medical information out there, then (the doctor) is obligated, as we are, under the rules of HIPAA [Health Insurance Portability and Accountability Act], of not going into detail."7

Fans became frustrated with the lack of information provided by the team, the media began to speculate when and if Johnson would return, and fantasy football owners of Johnson did not know whether they should drop or hold on to their top-five pick. ${ }^{8}$ Until recently, Johnson and the Chiefs kept everyone in the dark as to the exact nature of what turned out to be only a slight crack in one of Johnson's toes. ${ }^{9}$ Moreover, it remains unclear as to why the Chiefs and Johnson felt compelled to keep Johnson's injury a secret.

Johnson's situation highlights some of the problems, concerns, and misconceptions that arise when the sports industry addresses the Health Insurance Portability and Accountability Act ("HIPAA," alternatively the "Act"). Teams and organizations often struggle with what and how much information they can release to the public. ${ }^{10}$ As a result, fans and the media begin to speculate, which leads to the creation of a mystery injury. To best address the situation, one must weigh the importance of an individual's interest in protecting his or her personal health information with the interests of the athletic organizations, the media, and the public at-large. All things considered, sports organizations, with appropriate player authorization, should be permitted to release an athlete's sports-related injury information without breaching the constraints of HIPAA.

\section{A. The Issue}

Since the introduction of HIPAA in 1996, the multi-billion dollar sports

4. Stephania Bell, All Is Not Well in Kansas City, (Nov. 21, 2007), http://www.sports. espn.go.com/espn/pring?id=3121838\&type=blogEntry (last visited Aug. 9, 2008).

5. Id.

6. Covitz, supra note 2 (internal quotations omitted).

7. Id.

8. See James Alder, Types of Fantasy Football Leagues, AвоUT.COM: FoOTBALL, $\mathrm{http}: / /$ football.about.com/od/fantasygames/a/fantasyleagues.htm, for an explanation of fantasy football and the different league types (last visited Sep. 13, 2008).

9. Covitz, supra note 2.

10. See id. 
industry has been confronted by the need for a major overhaul in how it conducts business. " The Department of Health and Human Services ("DHHS") initially enacted HIPAA in an effort to shield an individual's Protected Health Information ("PHI") from unauthorized disclosures to third parties, to improve the quality of health care by restoring trust in the health care system, and to protect and enhance the rights of consumers by providing access to their health care information. ${ }^{12}$ With application to both public and private entities, HIPAA notably "requires extreme confidentiality of most medical information." "13 Further, HIPPA's implementation has impacted the technology age and the use of electronic systems to keep track of medical records in general. ${ }^{14}$

With the sports industry, HIPAA emphasizes the unavoidable exposure of the athlete-trainer relationship to the media. ${ }^{15}$ HIPAA's first purpose, shielding an individual's PHI from unauthorized disclosures to third parties, has exhibited the largest impact on sports organizations. ${ }^{16}$ As a result, those organizations have sifted through the initial misconceptions that surfaced upon implementation of the Act and have developed working models for protecting an athlete's PHI. ${ }^{17}$

\section{B. Roadmap}

This Note discusses the models implemented by athletic organizations in an effort to comply with HIPAA and protect the health information of athletes at both the professional and collegiate levels. To facilitate a better understanding of the organizational purpose behind the models, section II explains the general background information of the Act, covers necessary definitions found within the Act that pertain to athletic organizations, and offers an explanation of the information the Act is intended to cover. Section III offers an analysis of the different interests at play and weighs the importance of an individual's interest in protecting his or her PHI with the interests of athletic organizations, the media, and the public at large. Section IV introduces the different models

11. Susan M. Pitz, Features: HIPAA and the Sports Media: Separating Fiction from Reality, NEVADA LAWYER, Aug., 2003, at 12-13.

12. Id. at 12 (citing Preamble to the Health Insurance Portability Act of 1996, 65 Fed. Reg. 250 (Dec. 28, 2000)).

13. Susan K. Menge, Should Players Have to Pass to Play?: A Legal Analysis of Implementing Genetic Testing in the National Basketball Association, 17 MARQ. SPORTS L. REV. 459, 468 (2007).

14. See David R. Morantz, HIPAA's Headaches: A Call for a First Amendment Exception to the Newly Enacted Health Care Privacy Rules, 53 KAN. L. REV. 479, 481 (2005).

15. See generally Pitz, supra note 11, at 13.

16. See id.

17. Id. at 12-13 (noting that a few of the common misguided reactions to HIPPA's implementation were questions over whether or not sideline reporters would be able to report injuries to the television audience, whether or not teams would be able to release injury reports to the media, and whether or not coaches would be able to discuss the injury status of an athlete with the team's athletic trainer). 
that professional and collegiate sports organizations use in an effort to comply with the HIPAA guidelines. Section $\mathrm{V}$ discusses the different public policy arguments for and against releasing an athlete's injury information. Finally, sections VI and VII argue that the current models and systems used by athletic organizations remain appropriate. Sports organizations, with appropriate player authorization, should be allowed to release an athlete's sports-related injury information without breaching the constraints of HIPAA.

\section{HEALTH INFORMATION PORTABILITY AND ACCOUNTABILITY ACT}

To facilitate a better understanding of the organizational motivation for implementing certain models or requiring specific procedures for the release of an athlete's PHI, it is important to understand the details of HIPAA itself. This section explains the general background information of the Act, covers necessary definitions found within the Act that pertain to athletic organizations, and offers an explanation of the information the Act is intended to cover.

\section{A. General History}

HIPAA purports to protect an individual's health information. ${ }^{18}$ In the late 1990s, lawmakers and administrative agencies developed the Act in response to the emergence of information technology and the electronic medical record. ${ }^{19}$ The Act was created to ease growing concern among patients regarding the confidentiality of PHI records in an outdated paper record system. ${ }^{20}$ Additionally, the Act sought to address patient concern about where patient medical information was going and who had access to it. ${ }^{21}$

Congress approved the Act in $1996 .^{22}$ Upon approval of HIPPA, Congress required the secretary of the DHHS to recommend privacy measures to Congress within twelve months. ${ }^{23}$ Following the DHHS secretary's recommendations, Congress allowed itself a span of three years to fully develop legislation concerning the privacy of individually identifiable health information. ${ }^{24}$

18. Morantz, supra note 14 , at 481 .

19. Id. (referencing Lawrence O. Gostin \& James G. Hodge, Jr., Personal Privacy and Common Goods: A Framework for Balancing Under the National Health Information Privacy Rule, 86 MINN. L. REV. 1439, 1440 (2002) (describing the ongoing nature of the health industry's shift from paper to electronic records)).

20. Id. (referencing Lawrence O. Gostin, Health Information Privacy, 80 CoRNELL L. REV. 451, 453-54 (1995)).

21. See id. (referencing Gostin, supra note 20) (citing polling data that indicates $80 \%$ of respondents believed that consumers had lost control over the use and circulation of their medical information and $85 \%$ of respondents said that protecting the confidentiality of medical records is an essential part of national health care reform).

22. Id. (referencing Health Insurance Portability and Accountability Act of 1996, Pub. L. No. 104-191, 110 Stat. 1936 (codified at 42 U.S.C. $§ 201$ (2003)).

23. Id. (referencing 42 U.S.C. $\$ 264 a$ (2003)).

24. Morantz, supra note 14, at 481 (referencing 42 U.S.C. $\S 264(c)(1)(2003)$ ). 
As a condition of the three-year time allotment, Congress mandated that if the deadline passed with no legislation, the secretary of the DHHS would be required to develop the appropriate guidelines. ${ }^{25}$ Congress, however, missed its deadline. ${ }^{26}$ Consequently, the secretary of the DHHS, Donna Shalala, issued the proposed rule in November $1999^{27}$ and the final rule in December $2000 .^{28}$ In 2002, the new DHHS Secretary, Tommy Thompson, issued a notice of proposed rule making. ${ }^{29}$ Thompson issued the final rule, placing it into effect in August 2002. ${ }^{30}$

\section{B. Necessary Definitions and Covered Information}

This sub-section highlights the important HIPAA definitions pertaining specifically to sports organizations. It delves into what information HIPAA seeks to protect, which organizations fall under the purviews of the Act, the amount of allowed disclosure, and the role authorization plays in circumventing the Act's requirements. In addition, this sub-section addresses key concerns, particularly why HIPAA regulations apply to the sports organizations as a whole and not just to the team's physicians.

\section{Protected Health Information}

The DHHS initially enacted HIPAA in an effort to shield an individual's PHI from unauthorized disclosures to third parties. ${ }^{31}$ An individual's PHI includes any personally identifiable information concerning the past, present, or future physical or mental health or condition of an individual. ${ }^{32}$ Additionally, PHI also includes the provision of health care to an individual and the past, present, or future payment for that provision of health care. ${ }^{33}$ Therefore, an athlete's health information, both related and un-related to participation in a particular sport, falls under the purview of HIPAA. ${ }^{34}$ As such, HIPAA's protections extend to preventing the disclosure of the athlete's PHI to media outlets, the fans, and other third parties outside the sports organization with which

25. Id. (referencing 42 U.S.C. $§ 264(c)(1)$ (2003)).

26. Id.

27. Id. (referencing Standards for Privacy of Individually Identifiable Health Information, 64 Fed. Reg. 59, 918 (proposed Nov. 3, 1999)).

28. Id. (referencing 65 Fed. Reg. 82, 462 (Dec. 28, 2000)).

29. Id. at 481-82 (referencing 67 Fed. Reg. 14, 776 (proposed Mar. 27, 2002)).

30. Morantz, supra note 14, at 481 (referencing 67 Fed. Reg. 53, 182 (Aug. 14, 2002)).

31. Pitz, supra note 11, at 12 (citing Preamble to the Health Insurance Portability and Accountability Act of 1996, 65 Fed. Reg. 250 (Dec. 28, 2000)).

32. Morantz, supra note 14, at 481 (referencing Diane Kutzko et al., HIPAA in Real Time: Practical Implications of the Federal Privacy Rule, 51 DRAKE L. REV. 411 (2003) (citations omitted) (providing a thorough analysis of the law's mechanics and definitions)).

33. Id. (referencing Kutzko et al., supra note 32).

34. See June M. Sullivan, hipAA: A Practical Guide to the PrIVACy AND Security of HEALTH DATA 5 (American Bar Association) (2004). 
the athlete is associated. ${ }^{35}$

\section{What Constitutes a "Covered Entity"?}

Under the Act, organizations must complete several different steps in a process largely dependent upon whether they are classified as a "covered entity."36 The determination of what type of organization or association classifies as a covered entity provides for much of the misunderstanding of the Act, particularly in regard to who is responsible for compliance with the law. ${ }^{37}$ The regulations define a "covered entity" as a health plan, a health care clearinghouse, or a health care provider who transmits any health information in electronic form. ${ }^{38}$ Insurance companies, Medicaid, long-term care providers, employee welfare benefit plans, and portions of Medicare also fall within the definition of covered entities, ${ }^{39}$ as well as organizations that process health data and provide billing services. ${ }^{40}$ The remaining inquiry is whether a professional or collegiate sports organization constitutes a covered entity under HIPPA.

\section{a. Intercollegiate athletic community}

Initially, the intercollegiate athletic community assumed that HIPAA did not apply to its universities. ${ }^{41}$ Many universities assumed that they were exempt from HIPPA regulation because they are subject to the Family Education Rights and Privacy Act ("FERPA"), and HIPAA expressly exempts activities regulated by FERPA. ${ }^{42}$ Because HIPAA distinguishes traditional from nontraditional operations of universities, however, the universities' assumptions were wrong. ${ }^{43}$ Specifically, HIPAA exempts traditional university operations, such as student health centers run by university employees, but does not exempt non-traditional university operations. ${ }^{44}$ For example, the FERPA exemption would allow an athletic trainer to give information about a student athlete's PHI to the coach because HIPPA classifies this action as a traditional university operation. ${ }^{45}$ If an athletic trainer, however, gives an athlete's health information to the media and the media reports that information to the public, the FERPA exemption to HIPPA does not apply. ${ }^{46}$ HIPAA classifies this situation as a

35. See id.

36. Pitz, supra note 11, at 13.

37. Morantz, supra note 14, at 482 (referencing Pitz, supra note 11, at 13 (discussing confusion about whether HIPAA covers athletic teams)).

38. Pitz, supra note 11, at 12-13 (citing 45 C.F.R. $\$ 160.103$ (2002)).

39. Morantz, supra note 14, at 482 (citing 45 C.F.R. $\S 160.103$ (2002)).

40. Id.

41. Pitz, supra note 11, at 13.

42. Id.

43. Id.

44. Id.

45. Id.

46. Id. 
non-traditional operation - one that falls outside the traditional realm of treatment. ${ }^{47}$ In the absence of necessary authorization, disclosure of health information to a third-party creates an issue with regard to HIPAA compliance. ${ }^{48}$ As the foregoing discussion illustrates, intercollegiate athletic organizations constitute "covered entities" under HIPAA when they engage in non-traditional operations and release an athlete's PHI to third parties.

\section{b. Professional athletic community}

HIPAA treats professional sports organizations similarly, with the notable exception that professional sports organizations can never fall under the FERPA exemption. ${ }^{49}$ These organizations often create their own exemptions through the use of contractual waivers that allow the teams' athletic trainers to release PHI to management, owners, and coaches. ${ }^{50}$ The release of information within the organization constitutes a traditional operation. In addition, the contractual waiver often allows the teams to make certain injury information public. ${ }^{51}$ The release of information to third parties constitutes a non-traditional operation. Without the necessary authorization contained within the contractual waiver, HIPAA compliance would be an issue for these organizations. ${ }^{52}$ As a result, professional athletic organizations constitute covered entities under HIPAA when dealing with both traditional and non-traditional operations and the release of PHI.

\section{3. "Minimum Necessary" Disclosure}

HIPAA requires covered entities involved in the transmission, processing, or disclosure of PHI to limit disclosures made by the organization to the amount necessary for the purpose they seek to attain. ${ }^{53}$ The Act identifies this as the "Minimum Necessary" information requirement. ${ }^{54}$ The DHHS, through HIPAA, provides exceptions whereby covered entities can ignore this requirement and provide more than the minimum necessary amount. ${ }^{55}$ Moreover, the Act allows covered entities to breach this requirement in three specific situations. ${ }^{56}$ First, HIPAA allows a release of more than the minimum necessary

47. Pitz, supra note 11 , at 13.

48. Id.

49. See Menge, supra note 13, at 469.

50. See id. (citing Nat'l Basketball Ass'n, NBA Collective Bargaining Agreement (2005), art. XXII, § 3(a)-(c) [hereinafter NBA-CBA]).

51. See id.

52. See Sullivan, supra note 34 , at 14.

53. Morantz, supra note 14, at 482 (citing 45 C.F.R. $\S 164.502$ (b)(1) (2002)).

54. Id. (citing 45 C.F.R. $\S 164.502(\mathrm{~b})(1)$ ).

55. Id. (citing 45 C.F.R. $\S 164.502(b)(1)$ ).

56. See id. 
amount of PHI to health care providers providing treatment for a patient. ${ }^{57}$ Second, a covered entity may release more than the minimum necessary amount when an individual requests his or her own PHI. ${ }^{58}$ Lastly, such a disclosure is permissible when the individual authorizes the disclosure. ${ }^{59}$

Generally, sports organizations operate under the second and third exceptions to the release of the minimum necessary amount of PHI. An athletic organization may release more than the minimum necessary amount to the athlete who is the subject of the $\mathrm{PHI} .^{60}$ Additionally, an athlete-through the use of proper authorization forms - may authorize the organization to disseminate more than the minimum necessary amount of PHI to individuals within the organization as well as to outside third parties. ${ }^{61}$

\section{The Role of Authorization}

One way to circumvent the HIPAA regulations is to obtain an authorization form. ${ }^{62}$ To get around these regulations and to be able to disclose information to a third party, covered entities must obtain written acknowledgement from the injured player by using an authorization form that permits disclosures to exceed the "minimum necessary" requirement. ${ }^{63}$ The authorization form used by a particular organization must contain certain key elements and must not be a generic blanket authorization. ${ }^{64}$ Any compliance program seeking to address the intent of HIPAA will fail if it does not contain all of these elements within the contents of its authorization form. ${ }^{65}$

Various websites contain examples of basic authorization forms. ${ }^{66}$ Organizations must look to state law to determine whether additional measures, beyond HIPAA, are required to protect an individual's PHI. ${ }^{67}$ Even if an organization has obtained an effective authorization form, an individual may revoke that authorization in writing at any time. ${ }^{68}$ Further, players do not have to sign these authorization forms; treatment, payment, enrollment, or eligibility for benefits may not be conditioned on obtaining the authorization. ${ }^{69}$ To ensure compliance with HIPAA, covered entities must obtain an authorization that includes: (a) identification of the party authorizing disclosure, (b) a description of the PHI authorized for disclosure, (c) identification of the party(s) authorized to

57. Id. (citing 45 C.F.R. $\S 164.502(\mathrm{~b})(2)(\mathrm{i})$-(iii)).

58. Id.

59. Morantz, supra note 14 , at 482 .

60. See id.

61. See id.

62. See Sullivan, supra note 34 , at 14.

63. Pitz, supra note 11 , at note 3 .

64. Sullivan, supra note 34 , at 14.

65. Pitz, supra note 11, at 13.

66. Id. (citing 45 C.F.R. Subpart B $\S 160.201-205$ ).

67. Id.

68. Id.

69. Id. at note 3 . 
make use of the disclosures, (d) identification of the party(s) authorized to receive the disclosures, (e) a description of the exact purpose for disclosure, (f) a listed date or event causing the authorization to expire, and $(\mathrm{g})$ the date in which the individual signed the authorization. ${ }^{70}$

\section{a. Identification of the party authorizing disclosure}

One of the core requirements of a HIPAA-compliant authorization form is the signature and identity of the person authorizing disclosure of his or her PHI. ${ }^{71}$ Nothing within the Act requires the document to be notarized or witnessed, and a personal representative appointed to make health-related decisions for the individual may sign the document in the individual's place. ${ }^{72}$ HIPAA further requires the authorization document to contain a description of the personal representative's authority to act if the representative has signed the document for the individual. ${ }^{73}$ In relation to the sports industry, the authorization form must clearly identify the athlete and must be signed by the athlete or the athlete's personal representative. ${ }^{74}$

\section{b. A description of the protected health information authorized for dis- closure}

Another core requirement of the HIPAA-compliant authorization form is a specific and meaningful description of the PHI authorized for use and disclosure. ${ }^{75}$ HIPAA does not require the information to be specifically named; however, it must be named in such a way as to apprise the individual of the information authorized for disclosure. ${ }^{76}$

c. Identification of the party(s) authorized to make use of the disclosures

Another core requirement of the form is the identity of the individual or group authorized to use or disclose the PHI. ${ }^{77}$ HIPAA does not require an authorization form to name the specific person or entity authorized to make use of the disclosures, but instead, allows an individual to authorize disclosure to

70. Sullivan, supra note 34 , at $14-18$.

71. Id. at 14 .

72. Id.

73. $I d$.

74. See id.

75. Id. at 15 .

76. Sullivan, supra note 34 , at 15 (noting that an authorization allowing a covered entity to disclose an "entire medical record" or "complete patient file" remains valid; however, an authorization allowing disclosure of "all protected health information" fails for lack of specificity).

77. Id. at 16 . 
classes or categories of individuals or groups. ${ }^{78}$

\section{d. Identification of the party(s) authorized to receive the disclosures}

HIPAA grants the individual authorizing disclosure of PHI the right to know the recipients of that information, and the authorization form must designate the person or entity in which the covered entity plans to release information. $^{79}$ Instead of naming a particular person, the authorization form may designate a specific group of persons to whom the covered entity plans to disclose the information. ${ }^{80}$

\section{e. A description of the exact purpose for disclosure}

HIPAA requires an authorization form to provide a detailed description regarding each purpose for use and disclosure. ${ }^{81}$ For example, "for use during the term of athlete's contract authorizing the release of athlete's injury information related to athlete's participation in the sport," is an acceptable description.

\section{f. A listed date or event causing the authorization to expire}

To be HIPAA-compliant, an authorization form must designate either a date or an event that causes the authorization to expire. ${ }^{82}$ The date or event must bear some relation to the individual or purpose of the authorized use of PHI. ${ }^{83}$ The authorization form remains valid until the designated expiration date, absent a written revocation by the individual. ${ }^{84}$

\section{g. The date in which the individual signed the authorization}

In addition to a signature by the individual, HIPAA requires the authorization form to contain the date that the form was signed. ${ }^{85}$ Unless the authorization form expressly limits specific information, it authorizes a covered entity to disclose the identified information regardless of when the information was created. $^{86}$

78. Id. (noting that an authorization form may satisfactorily authorize disclosure with a document that authorizes disclosures "by any health plan, physician, health care professional, hospital, clinic, laboratory, pharmacy, medical facility, or other healthcare provider that has provided payment, treatment, or services to me or on my behalf" or an authorization form that simply authorizes disclosure "by all medical sources").

79. Id.

80. Id.

81. Id. at 18.

82. Sullivan, supra note 34 , at 18.

83. Id.

84. Id.

85. Id.

86. Id. 


\section{INTERESTS AT PLAY}

In order to participate at the highest performance level and provide the services expected of professional or collegiate athletes, an athlete's health is of paramount importance. ${ }^{87}$ As a result, athletic organizations and sports teams often require their players to undergo certain tests and performance evaluations to assure that the players will be physically able to perform at the highest attainable level. ${ }^{88}$ All too often, players succumb to injuries while enduring a lengthy season or participating in a weekly practice. Who should have a right to the results of these different tests, performance evaluations, and injury reports? In ascertaining an answer to this question, the importance of an individual's interest in protecting their PHI must be weighed against the interests of the athletic organizations, the media, and the public.

\section{A. The Athlete's Interest in PHI Confidentiality}

This section assesses an athlete's interest in keeping their PHI confidential, which represents the key purpose and goal of HIPAA. ${ }^{89}$ The Act seeks to protect the most personal information and requires extreme confidentiality. ${ }^{90}$ The protection of this information represents a strong interest of a traditional athlete. Information about a particular injury may be potentially embarrassing or something an athlete simply just does not want shared with the world. Further, in today's world of multi-million dollar contracts and lucrative free-agent dealings, athletes may want to minimize information that could decrease their overall free-agent or trade value to an organization.

In March 2006, Grady Jackson, an NFL football player, tested the freeagent market as an unrestricted free-agent. ${ }^{91}$ Jackson sought a new contract for the 2006 NFL season, and the Atlanta Falcons invited him to the organization's facilities for a visit. ${ }^{92}$ Jackson spent part of the time at the Falcons' facilities undergoing various medical examinations and tests as part of a physical. ${ }^{93}$ After one of the examining physicians recommended that Jackson be tested by a cardiologist, the Falcons notified Jackson and his agent that they wanted further testing on Jackson's heart before a decision would be made about any potential contract. ${ }^{94}$ The team gave Jackson no indication concerning whether or not he had failed his physical examination. ${ }^{95}$

87. Menge, supra note 13 , at 469.

88. Id.

89. See Pitz, supra note 11, at 12.

90. See id.

91. Brief for Plaintiff at 2, Jackson v. Atlanta Falcons Football Club, LLC, (N.D. Ga. 2007), (No. 07-cv-0939-GET) [hereinafter Jackson Brief].

92. Id.

93. Id.

94. Id.

95. Id. 
Two days after Jackson's examination at the Falcons' facilities, a member of the Falcons' organization allegedly told a reporter for a prominent sports media network that Jackson did not pass his physical examination. ${ }^{96}$ Further hastening the problem, a Falcons' personnel member also allegedly released additional PHI concerning Jackson. ${ }^{97}$ This initial report lead to the information being publicly reported by other prominent media networks, the national press, and numerous other outlets. ${ }^{98}$ All of the press reports contained PHI regarding Jackson's alleged heart problem. ${ }^{99}$

Jackson alleged that the reports caused him and his wife great concern for his health and negatively impacted any interest other NFL teams had in signing Jackson. ${ }^{100}$ Jackson noted that other NFL teams questioned him about the alleged heart condition during his visits with them. ${ }^{101}$ Additionally, two teams subjected Jackson to a series of extensive cardiology examinations. ${ }^{102}$ Five months after his first visit with the Falcons, Jackson opened negotiations and signed a contract with the team. ${ }^{103}$ Following the 2006 season, Jackson sued the Falcons' franchise for invasion of privacy and defamation over the alleged release of his PHI. ${ }^{104}$

This situation demonstrates why an athlete would want to protect the confidentiality of their PHI. Regardless of how the media obtained the information, it had a substantial impact upon the free-agent deal Jackson eventually obtained. The Falcons succeeded in hiring Jackson for far less than the 6.8 million dollars paid to a top five defensive tackle. ${ }^{105}$

Players should be able to authorize organizations to disclose information by waiving their HIPAA rights, but there should be a distinction between sports-related and non-sports-related injuries or conditions. Arguably, a greater interest exists in protecting the non-sports-related injuries and conditions. As in Jackson's case, this includes those injuries or conditions that occurred outside the realm of the sport in which the athlete participates. It should be up to the player to decide whether to make information unrelated to his participation in the sport publicly available, since such information has the potential to embarrass the player and possibly impact the player's free-agent value. In contrast, there is arguably a shared interest in obtaining sports-related injury information between the player, organization, and media.

96. Id. at 3 .

97. Jackson Brief, supra note 91, at 3.

98. Id.

99. Id.

100. Id.

101. Id.

102. Id.

103. Jackson Brief, supra note 91, at 3.

104. Jackson Files Suit Against Falcons, Disgruntled Tackle: Unusual for a Player Under Contract, Jackson Sues Team, Says Medical Records Wrongly Released, ATLANTA J.-CoNST., Mar. 28, 2007.

105. Id. (stating that Jackson signed a three year contract with a $\$ 300,000$ signing bonus, and the Falcons paid him the league veteran minimum salary for the 2006 season). 


\section{B. The Organization's Interest in Running a Business and Providing Infor- mation to the Media and the Public}

Athletic organizations have an interest in releasing an athlete's information to the media and the public. The sports industry is a multi-billion dollar industry, and the organizations that comprise it have a responsibility to keep their fans informed for a number of reasons. The question remains as to whether an organization's interest in running a business and providing information to the media and public sufficiently outweighs the player's interest in protecting his or her PHI. While an organization's interest does not outweigh the player's interest regarding non-sports-related injuries, it arguably does with injuries that result from participation in the sport. The growing sense of community created by sports teams and the use of stadiums funded largely by the public controls this conclusion.

\section{A Sense of Community}

To assure that all of the seats in the stadium are full when the first whistle blows, it is important for professional sports organizations to develop a good relationship with the community. Teams organize several events year-round to gain support and create the sensation that the team belongs to the community.

One example of community building occurred in the city of Arlington, Texas, home of the new Dallas Cowboys' stadium. ${ }^{106}$ When the first two arches supporting the retractable roof on the new stadium were completed, members of the Arlington City Council, the town's mayor, and other city officials joined the owner of the Cowboys to commemorate the event. ${ }^{107}$ The mayor told the news media that the city and the organization planned to celebrate several more milestones along the way. ${ }^{108}$ A number of teams also build rapport with the community by utilizing the star-power of their players and cheerleaders to participate in autograph signings, charitable events, and pep rallies.

After all of this effort and attention to make the community feel as though they own the team, keeping the public in the dark about the status of certain players may diminish some of that support. Organizations and teams could argue that they have a vested interest in keeping the fans and the media happy to effectively and efficiently run a business. Taking away the sports industry's ability to release injury information to the public could diminish the sense of community created by the team or organization, which could lead to a decrease in attendance and merchandise sales. Without fan attendance, merchandise

106. Another Milestone in the New Cowboys Stadium is Reached, http://www.arlingtontx. gov/cowboys/index.html (last visited Feb. 11, 2008) [hereinafter Cowboy's Milestone].

107. Id.

108. Id. 
sales, or the media to create hype for the games, the sports industry would arguably cease to exist.

\section{Taxing the Public to Build a New Stadium or Relocate}

In today's sports world, teams often garner funding from taxes and other sources of publicly funded revenue to build new stadiums or relocate to a new city. ${ }^{109}$ This adds to the sense that teams are a part of the community and that they owe it to the community and the fans to inform them of the injury status of their favorite players. The amount of money traditionally given to a team from the public to build a new stadium or relocate to a new city varies on a case-bycase basis.

For example, the Arizona Cardinals recently built a new stadium with an overall cost of approximately $\$ 455$ million. ${ }^{110}$ The Arizona Sports and Tourism Authority contributed over $\$ 300.4$ million to the cost of the stadium, and the team fronted the rest of the cost of construction. ${ }^{111}$ In addition to the overall funding costs, the stadium project sought to provide added economic benefits to the area. ${ }^{112}$

In Texas, the Dallas Cowboys recently completed negotiations for the funding of a stadium that will house the team in 2009. ${ }^{113}$ Under the terms of the original funding and closing agreement between the Dallas Cowboys and the City of Arlington, the organization and the city were to each pay up to half of the total project cost of $\$ 650$ million. ${ }^{114}$ Further, the organization agreed to pay for any overruns that occurred during construction. ${ }^{115}$ Since the date of the original agreement, the stadium's estimated cost has jumped to one billion dollars; the city and organization expect the stadium to be one of the biggest and best of its kind. ${ }^{116}$ The stadium should fulfill the city's expectations of elevating the city's profile and attracting marquee events. ${ }^{117}$

As a result of the large amount of public funding for these stadiums and other sports venues throughout the United States, the public feels entitled to all

109. See id.

110. University of Phoenix Stadium-Statistics, http://www.universityofphoenixstadium. com/index.php?page=stadium_facts\&section=statistics (last visited Feb. 11, 2008).

111. Id.

112. Id. (noting that the stadium's construction phase increased the area's economic benefit by $\$ 400$ million and added 3,500 jobs. $\$ 20$ million will be given to the Arizona State General Fund throughout the construction period. Further, the team contributes approximately $\$ 150$ million to the area's yearly economic output).

113. Cowboy's Milestone, supra note 106.

114. Id.

115. See id.

116. Michael Granberry, New Stadium May Widen Social Divisions: Cowboys Officials Say Venue Will Offer Fun for All Fans, but Some Aren't so Sure, THE DaLlas MORNING NEWs, Dec. 10, 2006, available at $\mathrm{http}: / / \mathrm{www}$.dallasnews.com/sharedcontent/dws/news/localnews/cowboys stadium/stories/121006dnmetgenerations.32ef5cf.html.

117. Id. 
of the information about these organizations. ${ }^{118}$ This feeling of entitlement extends to the release of injury information related to an athlete's participation in the sport. To satisfy this feeling of entitlement, teams have an interest in releasing information regarding sports-related-injuries to the media and public.

\section{The Indianapolis Colts}

Over the past few years, someone living in Indianapolis would be hard pressed to avoid the "Make it Personal" or "Blue Nation" signs, billboards, and radio advertisements throughout the city. The Indianapolis Colts (the "Colts") also sponsor numerous community-building events in the convention center, in stores throughout the city, and on Monument Circle. Other activities include: children's games, free concerts, and autograph signings.

The Colts moved to Indianapolis nearly twenty-four years ago. ${ }^{119}$ After failed attempts to reach an agreement with the city of Baltimore to build a new stadium, then-owner Robert Irsay, packed up the team in the middle of the night and moved it to Indianapolis. ${ }^{120}$ Irsay recognized the move as the team's only option, after stalled negotiations for a new Baltimore stadium. ${ }^{121}$ On the other end of the move, Indianapolis and a new stadium awaited.

Originally known as the Hoosier Dome, the total cost of construction for the RCA Dome was $\$ 77.5$ million. ${ }^{122}$ The Lilly Endowment and the Krannert Charitable Trust contributed $\$ 30$ million toward the cost of construction, and the city financed the remainder by selling $\$ 47.2$ million in bonds. ${ }^{123}$ Despite the recent construction of a new stadium to replace the RCA dome, Indianapolis still owes a principal of approximately $\$ 75$ million on bonds related to the RCA Dome's construction. ${ }^{124}$ The city uses a Marion County restaurant tax to

118. See generally Update: Sports-Stadium Funding, ISSUES AND CONTROVERSIES, Aug. 23, 2008, available at http://personal.ecu.edu/aldermand/geog2019/stadium_funding_issue.html (indicating that the combination of publicly funded stadiums and a partial government anti-trust exemption given to professional sports leagues elevates the public interest to such a level that even Congress may become involved); see also, e.g., Lester Munson-Specter's Inquiries Put NFL's Lucrative Broadcast Structure in Play, http://sports.espn.go.com/nfl/columns/story? columnist=munson_lester\&id=3226250 (discussing Senator Arlen Specter's investigation into the NFL's Spygate Scandal, in which the New England Patriots were caught illegally video taping the opposing sidelines defensive signals) (last visited Feb. 9, 2009); see also, e.g., ESPN.COMLeaders of House Subcommittee Contact Mitchell, http://sports.espn.go.com $/ \mathrm{mlb} / \mathrm{news} /$ story?id=2749552 (discussing Congressional involvement in the investigation of steroid use in baseball) (last visited Feb. 9, 2009).

119. Jarrett Bell, As Colts Return to Baltimore, Owner Irsay Says Leave the Past Behind, USA TODAY, Jan. 11, 2007, available at $h$ ttp://www.usatoday.com/sports/football/nfl/colts/2007 -01-10-baltimore_x.htm.

120. Id.

121. Id.

122. City Still Owes $\$ 75$ Million on Soon-To-Be Demolished RCA Dome, SoutH BEND TRIBUNE, Oct. 29, 2006, available at $\mathrm{http} / / / \mathrm{blogs}$.thenewstribune.com/index.php/all/2008/02.

123. Id.

124. Id. (noting that the city intended for the RCA Dome to be paid off by 2013; however, several refinancing measures and term extensions moved the payoff date to 2021 , which is thir- 
raise a portion of the money used to pay those bonds. ${ }^{125}$

Despite still owing on bonds attributed to the RCA Dome, the city of Indianapolis entered into an agreement with the Colts to build the new Lucas Oil Stadium. ${ }^{126}$ The stadium will act as the new home of the Colts, house National Collegiate Athletic Association ("NCAA") men's and women's basketball events, and be utilized for major conventions. ${ }^{127}$ The estimated stadium cost of around $\$ 700$ million is being funded by a joint fundraising venture by the State of Indiana and the City of Indianapolis, with the Colts organization providing $\$ 100$ million. ${ }^{128}$ Marion County, in order to provide for its share of the stadium costs, raised taxes on food and beverage, auto excise, inn keeping, and admission. ${ }^{129}$ A one-percent increase in food and beverage taxes in six counties surrounding Marion County and the sale of license plates bearing the Colts' logo completes the total. ${ }^{130}$ The city anticipates reaping a number of economic benefits from the new stadium. ${ }^{131}$

As a result of the sense of community created by the Colts organization and the significant amount of public funds used to fund both the RCA Dome and Lucas Oil Stadium, the organization retains a significant interest in maintaining the public's support. Because the stadiums were both heavily funded using public money, the fans arguably have a right to know much of the information relating to the team. The Colts organization also has an interest in providing that information. The question remains as to whether the organization's interest in running a business and maintaining public support outweighs the individual athlete's interest in protecting his PHI. While the organization's interest does not outweigh the player's interest regarding non-sports-related injuries, it arguably does regarding injuries that result from participation in the sport. The growing sense of community created by the Colts organization and by the publicly funded stadiums supports this conclusion.

In 2006, an injury by one of the Colt's players, Corey Simon, provided an illuminating example of these competing interests at work. On October 5, 2006, the Colts placed Simon, a defensive tackle, on the NFL's non-football injury list. ${ }^{132}$ Although Simon had not practiced since injuring his knee during training camp in August 2006 and subsequently undergoing arthroscopic sur-

teen years after the city and organization tore down the RCA Dome and moved into Lucas Oil Stadium).

125. Id.

126. Id.

127. Lucas Oil Stadium Fact Sheet, IN.Gov, available at http://www.ingov/iscba/2371. htm.

128. Id.

129. Id.

130. Id.

131. Id. (noting that the new stadium will keep the Colts in Indianapolis with a new longterm contract, create room to expand the city's convention center, provide $\$ 2.25$ billion in economic benefits to the area, and lead to the creation of 4,200 new permanent jobs and 4,900 temporary construction jobs).

132. Tom James, Colts' Corey Simon out for Season, TRIBUNE STAR, Oct. 6, 2006 available at http://www.tribstar.com/sports/local_story_279001022.html. 
gery, the Colts organization noted in a prepared statement that Simon's inactivity did not relate to the game of football. ${ }^{133}$ Colts' team president, Bill Polian, issued a statement noting that "[i]n deference to Corey's privacy and in compliance with federal medical privacy laws, we may not discuss the particulars of Corey's condition other than say it is an illness [and] not an injury and is unrelated to the knee surgery he had in August. It is not football-related."134 Any further information provided by the organization remained ambiguous, and the organization offered no insight into the nature of the illness or possible treatment options. ${ }^{135}$

The lack of information released by the team regarding Simon led to a wide range of speculative thoughts on the part of fans and the media, creating a mystery injury or illness. A number of fans expressed anger and confusion over why the organization insisted on keeping them in the dark about one of the team's veteran players. One fan even went so far as to paint a big red " $x$ " on his Corey Simon jersey and tape it to the front of the bus he and his friends used for tailgating. Media outlets ran reports speculating that Simon had polyarthritis; however, despite all of this, the Colts organization would not release information relating to the team-designated non-football injury.

Despite the anger, confusion, and speculation it created, the Colts organization handled the matter both professionally and legally. The organization stayed within the purviews of the NFL's Collective Bargaining Agreement and Settlement Agreement by respecting Simon's privacy and complying with the federal medical privacy laws. Ultimately, however, the action taken by the Colts organization in not releasing Simon's injury information supports the conclusion that teams should be able to release information about injuries that are related to the sport. No one contests that organizations should not be able to release information about non-sport's related injuries, as the player's interest in protecting their PHI regarding injuries unrelated to participation in the sport outweighs the interests of the organization in satiating the public's appetite for such information. If Simon's inactivity resulted from the knee injury he suffered during training camp, the injury is related to his participation in the sport and the public's sense of entitlement to the injury information would arguably be greater.

\section{The Green Bay Packers}

In discussing the sense of community created by professional sports organizations seeking to maximize revenue and fill seats, the Green Bay Packers organization is in a unique situation. Owned by the city of Green Bay and the Green Bay and Brown County Professional Football Stadium District, ${ }^{136}$ the

133. Id.

134. Id.

135. Id.

136. Lambeau Field-Stadium Info, http:/www.lambeaufield.com/stadium_info/history 
Packers organization faces the biggest challenge in dealing with the release of player information to the fans and the media, as there exists a large public sense of entitlement to that information.

The tradition of Lambeau Field, the Packers' stadium, began with the opening kickoff in 1957 and continues to this day. ${ }^{137}$ The ownership structure of the team, along with the often cold and hostile weather conditions, has fostered the growth of that tradition throughout the years. ${ }^{138}$ Games such as the infamous Ice Bowl, played between the Packers and the Dallas Cowboys on December 31,1966, add to the rich history that has led to Lambeau Field being coined as the Frozen Tundra. ${ }^{139}$ Lambeau Field, with an active tenure of fifty years, sits at the top of the list of the longest continually occupied NFL stadiums and registers a respectable third on the list for the longest home field tenures in all professional sports. ${ }^{140}$ Adding to the organization's interest in sharing information with the media and the fans, the Packers have managed to successfully sell out on a season ticket basis since 1960 and continue to accumulate names for the ticket waiting list every season ${ }^{141}$ The Packers organization authorizes season ticket holders to transfer their season tickets to qualifying heirs and transferees upon notarized authorization on an official transfer form. $^{142}$

As a result of the traditions surrounding the organization and the sense of community created by city ownership, the Packers' interest in running a business and providing information to the media and public arguably outweighs the players' interest in protecting their PHI. That business interest, however, only goes so far and should only extend to PHI that relates to the athlete's participation in the sport. Information relating to non-sports related injuries should remain private, as an athlete's interest in protecting that information outweighs any interest of the organization because it does not directly relate to the athlete's participation in the sport.

(last visited Feb. 11, 2008) [hereinafter L.F. Stadium Info].

137. Id.

138. Id.

139. Pro Football History-The Ice Bowl, http://www.profootballhof.com/history/decades/ 1960s/ice_bowl.jsp (noting that 50,000 fans braved the elements for the Ice Bowl despite the game time temperature registering thirteen degrees below zero) (last visited Feb. 11 2008). See also NFL Championship Game, 1967, http://en.wikipedia.org/wiki/NFL_Championship Game, 1967 (last visited Feb. 11, 2008). The game's officials stopped using their whistles following the opening kickoff after the referee who blew his metal whistle to signal the start of the game had his whistle freeze to his lips. The officials utilized voice commands to officiate the rest of the game. $I d$.

140. L.F. Stadium Info, supra note 136. The Boston Red Sox have occupied Fenway Park for ninety-five years, and the Chicago Cubs organization has made Wrigley Field its home for ninety-three years. Id.

141. Lambeau Field-Events Info, http:/www.lambeaufield.com/events_info/packers game_tickets (last visited Feb. 11, 2008). Tickets.

14․ See id. for the exact language of the Official Policy on Transfer of Packers Season 


\section{The Public's Interest in Obtaining Information and Knowledge About Individuals Who Have Placed Themselves in the Public Eye}

This section discusses whether or not an athlete's decision to play sports at a collegiate or professional level should constitute a waiver of his or her privacy rights, making his or her PHI a matter of public concern. The sense of community created by sports organizations and the growing trend toward publicly funded stadiums add to the sense of public entitlement to an athlete's injury information. In addition, the question arises as to whether an athlete's participation in a sport places the athlete in the public eye and causes any information about that athlete to become a matter of public concern. This requires a balancing of the player's interest in keeping PHI private with the public's interest in staying apprised of information about a public figure.

While the public's interest does not outweigh the player's interest regarding non-sports-related injuries, the same conclusion is not as clear regarding the public's interest in information about injuries that result from participation in the sport. The growing sense of community created by sports teams, the use of stadiums funded largely by the public, and the public's interest in staying apprised with information relating to a public figure all complicate this inquiry.

A person or entity releasing information about another's private life avoids liability to the other for invasion of privacy if the information would not be overly offensive to a reasonable person and is a matter of legitimate public concern. ${ }^{143}$ Generally, an individual's right to privacy is secondary to the public interest in obtaining information of public concern, and, in today's society, actions taken by public figures become matters of legitimate public concern. ${ }^{144}$

Subsequently, when the media reports on information about a collegiate or professional athlete's PHI, the athlete has no available tort action against the media, unless the information reported was knowingly false. ${ }^{145}$ Additionally, the media does not constitute a covered entity under HIPAA and would not be liable for the release of information. ${ }^{146}$ Sports organizations, however, do constitute as covered entities under HIPAA, and athletes would arguably have an action in tort against a sports organization for the unauthorized release of a player's PHI.

Because injury information pertaining to an athlete's participation in the sport is arguably a legitimate public concern, sports organizations should be able to release that information with proper authorization. ${ }^{147}$ Injury information not pertaining to an athlete's participation in the sport, however, should be protected because it is potentially offensive and private information that should not

143. RESTATEMENT (SECOND) OF TORTS $§ 652 D$ (1976).

144. Sidis v. F-R Publ'g Corp., 113 F.2d 806 (2d Cir. 1940).

145. See id.

146. See Pitz, supra note 11 , at 12 .

147. See RESTATEMENT (SECOND) OF TORTS § 652D (1976). 
be released to third parties. ${ }^{148}$

\section{AN ATTEMPT AT COMPLIANCE: ORGANIZATIONAL MODELS}

While an athlete's injuries, both on and off the field, often raise questions related to medical information privacy, it appears that professional and collegiate athletes have agreed to be subject to a different standard of privacy. ${ }^{149}$ The following section explains the role and use of different organizational models and analyzes their effectiveness in complying with HIPAA.

\section{A. National Basketball Association Collective Bargaining Agreement}

The National Basketball Association ("NBA") represents one industry dominated largely by collective bargaining. ${ }^{150}$ Policies found within the NBA's Collective Bargaining Agreement ("CBA") arise from negotiations between the NBA and the National Basketball Player's Association ("NBPA"). Many of the policies applied to the league's players come as a result of the league's CBA. ${ }^{151}$ A player cannot contest or challenge these policies. ${ }^{152}$ While, on its face, HIPAA may appear to pose a problem for the NBA in releasing a player's injury information to the media or the public without the player's consent, the NBA's CBA acts as a contractual waiver of the player's HIPAA rights - at least with regard to release by the team's management. ${ }^{153}$

As a result, the CBA gives teams and organizations the authorization to acquire any information regarding a player's past or present medical condition. ${ }^{154}$ This includes a player's past medical history and current health problems. ${ }^{155}$ The CBA authorizes a team physician to "disclose all relevant medical information concerning a player to (i) the General Manager, coaches, and trainers of the Team ..." and to "(ii) any entity from which any such Team seeks to procure, or has procured, an insurance policy covering such player's life or any disability, injury, or illness." 156 In addition to the disclosure of information within the confines of the team, the CBA also permits trainers, team officials, and athletic organizations to make such information public. ${ }^{157}$ The information released to the public, however, must be in relation to the "reasons why any such player has not been or is not rendering services as a player." ${ }^{158}$ Essential-

148. See id.

149. Menge, supra note 13 , at 469.

150. Id.

151. Id.

152. Id.

153. Id. (citing NBA-CBA, supra note 50).

154. Id. (citing NBA-CBA, supra note 50).

155. Menge, supra note 13, at 469 (citing NBA-CBA, supra note 50).

156. Id. (internal quotations omitted).

157. Id.

158. Id. (internal quotations omitted). 
ly, this provides teams with the authority to circumvent the HIPAA guidelines and release injury reports. Moreover, as a result of the CBA, teams in the NBA may release information to the public that explains why a player will not be playing in a particular game or information regarding the specific medical reasons for the organization's termination of a player. ${ }^{159}$

\section{B. National Football League Collective Bargaining Agreement}

Prior to the implementation of HIPAA, individuals speculated as to how the NFL would react to the final regulations. ${ }^{160}$ The NFL had three options. ${ }^{161}$ First, it could challenge the Act's constitutionality. ${ }^{162}$ Second, the League could obey the law and stop releasing injury reports. ${ }^{163}$ Third, the league and NFL Players Association could include a provision in the collective bargaining agreement that authorizes the release of injury information. ${ }^{164}$

After HIPAA was enacted, the NFL made no attempt to challenge the constitutionality of the Act, and it continues to release injury reports every week during the season. In addition, the league's CBA does not contain an authorization for the release of PHI. ${ }^{165}$ It is possible that this information is contained within the Stipulation and Settlement Agreement incorporated within the CBA; however, the NFL does not make that Agreement public. ${ }^{166}$

The league's approach to the release of injury information is best analyzed by considering the approaches that individual teams take. The approach taken by the Kansas City Chiefs in dealing with Larry Johnson's injury and by the Indianapolis Colts in dealing with Corey Simon's injury, while representing different approaches, provide insight into the league's approach. With Johnson, the Chiefs refused to release information related to Johnson's injury and cited HIPAA privacy laws despite the injury being related to his participation in the sport. ${ }^{167}$ The NFL, however, does not customarily cite HIPAA in regards to on-field injuries. ${ }^{168}$ Typically, teams in the NFL take the approach used by the Colts in dealing with Simon-limited disclosure to the degree it pertains to an athlete's participation in the sport. ${ }^{169}$

159. Id.

160. New Law Could Hamstring NFL on Injury Reports, ThE SAN DIEGoUNiON-TRIBUNE, June 16, 2002, available at http://www.foley.com/publications/pub_etail.aspx?pubid=1260.

161. Id.

162. Id.

163. Id.

164. Id.

165. Nat'l Football League, NFL Collective Bargaining Agreement Between the NFL Management Council and the NFL Players Association, (2006), http://www.nflplayers.com/ images/fck/NFLCOLLECTIVEBARGAININGAGREEMENT2006-2012.pdf [hereinafter NFLCBA] (last visited Feb. 11, 2008).

166. Id.

167. Covitz, supra note 2.

168. Id.

169. James, supra note 132. 
The fact that the NFL even allows teams to place players on a nonfootball-injury list, a list that does not require the team to report the specific nature of the injury, suggests that teams are not authorized to release information about injuries unrelated to a player's participation in the sport. Further, the NFL's standard practice is to release information relating to a player's participation in the sport and refuse to release information unrelated to that participation. $^{170}$

\section{National Collegiate Athletic Association}

This section discusses the use of authorization forms for collegiate athletes in order to facilitate compliance with HIPAA in regards to the nontraditional operations of an intercollegiate athletic organization. In particular, this section introduces and breaks down two different types of authorization forms and methods.

\section{Butler University Sports Medicine Standard Authorization Form}

Butler University, located in Indianapolis, Indiana, participates in NCAA Division I athletics. ${ }^{171}$ To comply with HIPAA regulations, the university's Sports Medicine program requires intercollegiate athletes to sign a consent form when disclosing information to third parties. ${ }^{172}$ As noted before, HIPAA only requires intercollegiate institutions to obtain authorization for the release of information relating to non-traditional university operations because the Act exempts traditional university operations. ${ }^{173}$

Butler's authorization form requires identification of the athlete and the person or persons authorized to release PHI. ${ }^{174}$ In addition, the form asks the athlete to name the specific information that may be released and to whom. ${ }^{175}$ The authorization form states the purpose of the authorized disclosures by noting that "[a]ttendance and progress will be reported to the above on a weekly basis or as specified below," clearly stating the purpose of the disclosure. ${ }^{176}$ The form requires the athlete's dated signature and also notes that the authorization expires sixty days after being signed. ${ }^{177}$ The document meets each core

170. See id.

171. Butler University Sports, http://butlersports.cstv.com/index-main.html (last visited Jan.29, 2009).

172. Butler University Sports Medicine-Consent to Release Information, http://butler sports.cstv.com/auto_pdf/p_hotos/s_chools/butl/genrel/auto_pdf/SportsMedRelease [hereinafter Butler Consent] (last visited Feb. 11, 2008).

173. See Pitz, supra note 11, at 13.

174. Butler Consent, supra note 172.

175. Id.

176. Id.

177. Id. 
requirement of a HIPAA-compliant authorization form. ${ }^{178}$

\section{Notice Plus Informed Consent Model}

The notice plus informed consent model represents another model that sports organizations could implement to ensure compliance with HIPAA regulations. ${ }^{179}$ This model suggests that intercollegiate or professional sports organizations provide a notice to student athletes to inform them that information relating to their participation in the sport would be released. ${ }^{180}$ Following the notice, the sports organization would present an informed consent document for the athlete to sign. ${ }^{181}$ The informed consent document would specifically authorize the release of the requested information. ${ }^{182}$

Such a model would likely comply with the requirements of HIPAA. Because the notice and informed consent models both request the disclosure of specific information, neither would be considered blanket authorizations. ${ }^{183}$ Organizations would simply have to assure that the documents include other required information, such as the athlete's name and dated signature, the purpose for the agreement, an expiration date, and information on the persons or entities authorized to use and receive the information. ${ }^{184}$

\section{National Athletic Trainers' Association}

Around August 2003, the National Athletic Trainers' Association ("NATA") suggested that athletic trainers working for sports organizations and colleges require athletes to sign authorization forms prior to every event in which the athlete could potentially be injured and that the injury information should somehow be disclosed to the media. ${ }^{185}$ The recommendation arose out of the fear that an authorization form covering more than one event would be considered a blanket authorization and would not be HIPAA-compliant. ${ }^{186}$ This fear, however, arises from confusion over what exactly constitutes a blanket authorization.

A blanket authorization is an authorization form that remains generic in nature and lacks specificity. ${ }^{187}$ For example, an authorization form releasing all protected health information would be considered a blanket authorization and

178. See Sullivan, supra note 34.

179. See Pitz, supra note 11 , at 12-13.

180. Id. at 13.

181. Id.

182. Id.

183. See Sullivan, supra note 34 , at 14.

184. See id.

185. Pitz, supra note 11 , at 13 .

186. Id.

187. See Sullivan, supra note 34 , at 14. 
would not be deemed HIPAA-compliant. ${ }^{188}$ Moreover, HIPAA does not require athletic trainers and sports organizations to require athletes to sign authorization forms before every game. ${ }^{189}$ As long as the authorization form specifically indicates which information is to be released, the party authorized to release the information, the party authorized to receive the information, and contains the other required information (i.e. name, purpose, signature date, and expiration), it will comply with HIPAA guidelines. ${ }^{190}$

\section{Public Policy Rationale}

This section discusses the competing public policy rationales driving the debate over whether to allow the release of injury information relating to an athlete's participation in a sport through the use of appropriate authorization forms.

\section{A. The Promotion of Betting Lines and Gambling}

One argument against releasing injury reports is that individuals may easily utilize these reports to create betting lines or to gamble on college or professional sports. ${ }^{191}$ Sports betting is a popular form of gambling that generates billions of dollars annually. ${ }^{192}$ In the United States, Nevada remains the only state to allow sports betting; however, the boom of internet gambling sites creates an alternative vehicle for sports gambling. ${ }^{193}$ These sites offer sports gamblers the opportunity to place a bet with a company located in a country that legally permits such betting. ${ }^{194}$

Supporters of legalized gambling classify it as a harmless diversion and argue that people should be able to do what they please with their earned income. ${ }^{195}$ Proponents also argue that legalized gambling generates economic benefits, such as investment opportunities and jobs, tax revenue to the surrounding community, and increased tourism. ${ }^{196}$

Opponents of legalized gambling often focus on the various social ills that gambling arguably fosters. ${ }^{197}$ Gambling is a compulsive habit that disproportionately affects economically disadvantaged individuals and may lead to an

188. See id.

189. See id.

190. See id.

191. Pitz, supra note 11, at 13.

192. William N. Thompson, Gambling, Microsoft ENCARTA OnLINE ENCYCLOPEDIA (2008), available at http://encarta.msn.com/text_761560772__0/Gambling.html [hereinafter Sports Betting].

193. Id.

194. Id.

195. Id.

196. Id.

197. Id. 
increase in crime and the corruption of political and law enforcement officials. ${ }^{198}$ In addition, gambling could increase the potential of fixed or illegally influenced sporting events. ${ }^{199}$

As it relates to this Note, the relevant inquiry is whether the release of injury reports supports the creation of betting lines and gambling on individual sporting events. A simple search of one internet gambling site reveals information pertaining to a team's injuries, recent transactions, offensive and defensive statistics in comparison to the rest of the league, and the results of the team's previous games. ${ }^{200}$ The overwhelming amount of non-injury information available and the significant number of other factors that go into the creation of betting lines suggests that it is unlikely that stopping teams from releasing injury reports would lead to a dramatic decrease in gambling. These considerationsin addition to a sports organization's interest in running a business and satiating the media and the public, along with the public's interest in obtaining information relating to an athlete in the public eye-may override public policy concerns related to the release of injury reports.

\section{B. Contractual Waiver of Protected Health Information}

A second public policy inquiry is whether a player should be allowed to waive or contract away their HIPAA rights with a contractual waiver. The central issue is the enforceability of such a contractual waiver, which gives rise to the question of whether a contract between a sports organization and an athlete contracts away too much information with regard to the athlete. Courts have often held contracts dealing with information and issues overly personal to the parties unenforceable, noting that the legal system does not want to entangle itself with such personal decisions. ${ }^{201}$

In addition, the contractual waivers used by professional sports organizations often fail to include a specific expiration date, which calls into question the validity of the authorization form. ${ }^{202}$ Furthermore, this section also analyzes the substance and form of such waivers.

\section{Non-sports-related Injuries}

The DHHS initially enacted HIPAA in an effort to shield the past, present, and future physical or mental health conditions of an individual from

198. Sports Betting, supra note 192.

199. Id.

200. Bodog - NCAA College Basketball Butler, http://www.bodoglife.com/bettingteams/ncaa-college-basketball/46 (last visited Feb. 11, 2008).

201. See, e.g., 7 RICHARD A. LORD, WILLISTON ON CONTRACTS $\S 16$ (4th ed. 2008) (discussing bargains tending toward unenforceability as a result of their personal nature, including surrogacy agreements, agreements dealing with religion, and bargains in restraint of marriage).

202. See NBA-CBA, supra note 50; see also NFL-CBA, supra note 165. 
unauthorized disclosure to third parties. ${ }^{203}$ As a result, HIPAA pertains to injuries that are both related and unrelated to an athlete's participation in a particular sport. In dealing with the contractual waiver of such personal information, one must analyze whether the information is too personal to the individual for the contract to be enforceable.

Arguably, an athlete holds a greater interest in protecting information not related to participation in the sport, and a contract waiving the release of such information should be deemed too personal and unenforceable. The fact that an injury occurs outside of the scope of an athlete's participation in the sport devalues the sense of entitlement attributed to the sports organization's interest in running a business and the public's interest in gaining access to information of public concern. It gives greater weight to the athlete's interest in keeping their $\mathrm{PHI}$ private. As a result, a contract authorizing an athletic organization to release information unrelated to an athlete's participation in the sport should be held void as against public policy.

\section{Sports-related Injuries}

A different analysis is required when addressing injuries related to an athlete's participation in the sport. Arguably, the information is of a less personal nature. While this information is still personal in the traditional sense, the fact that the injury occurred within the scope of the athlete's participation in the sport increases the weight that should be given to the sports organization's interest in running a business and the public's interest in gaining access to information of public concern. A contractual waiver authorizing the release of such information should be deemed enforceable and courts should not find such a contractual waiver unenforceable for public policy concerns.

\section{Expiration}

In order to be HIPAA-compliant, an authorization form or contractual waiver must designate either a date or an event that causes the authorization to expire, and the event must bear some relation to the individual or purpose of the authorized use of $\mathrm{PHI}$. $^{204}$ The CBAs implemented by most professional sports leagues often act as an overarching agreement that pertains to all of the leagues' players. ${ }^{205}$ Such agreements, however, lack specificity regarding the expiration of the agreement in relation to an individual athlete.

Despite lacking specificity regarding the agreement in relation to an individual athlete, two elements of the CBA make it sufficiently specific to be HIPAA-compliant. First, the agreements between the player's association and

203. Pitz, supra note 11, at 12 (citing Preamble to the Health Insurance Portability and Accountability Act of 1996, 65 Fed. Reg. 250 (Dec. 28, 2000)).

204. Sullivan, supra note 34, at 18.

205. See Menge, supra note 13, at 469. (citing NFL-CBA, supra note 165). 
the respective leagues contain expiration dates of their own. ${ }^{206}$ Since these agreements contain the release of PHI, the expiration dates for these agreements constitute the expiration dates for the authorizations. Second, the CBA of a respective league applies only to players under contract with a team in that league. ${ }^{207}$ Further, the termination of a player's contract with a particular team could be viewed as an expiration event, which satisfies the expiration requirement for a HIPAA-compliant authorization form. ${ }^{208}$

\section{Blanket Authorizations}

A third public policy argument is whether blanket authorizations should be considered HIPAA-compliant. A blanket authorization represents an authorization form that remains generic in nature and lacks specificity. ${ }^{209}$ For example, an authorization form releasing all PHI would be considered a blanket authorization and would not be HIPAA-compliant. ${ }^{210}$ Such an authorization fails to meet the specificity requirements contained within HIPAA and would allow an organization to release any mental or physical health information of an athlete. ${ }^{211}$ While an organization should be able to release information relating to the athlete's participation in a particular sport, authorizing an organization to release any information exceeds the confines of valid HIPAA authorization.

The authorization form must specifically denote the information to be released, the party authorized to release the information, and the party authorized to receive the information, as well as name, purpose, signature date, and expiration, in order to succeed under the purviews of HIPAA. ${ }^{212}$ Blanket authorizations remain too general and authorize the release of too much $\mathrm{PHI} .{ }^{213}$ Sports organizations, in order to remain HIPAA-compliant, should make sure to specifically connote the information authorized for release within the authorization form or contractual waiver.

\section{ARGUMENT}

In dealing with an athlete's PHI, collegiate and professional sports organizations manage information concerning injuries both related and unrelated to the athlete's participation in the sport. The question arises as to what injury information, if any at all, these organizations should be able to release to third parties. The importance of an individual's interest in protecting his or her PHI

206. See NBA-CBA, supra note 50; see also NFL-CBA, supra note 165.

207. See id.

208. See Sullivan, supra note 34 , at 14.

209. See id.

210. See id.

211. See id.

212. See id.

213. See id. 
must be weighed against the interests of the athletic organizations, the media, and the public at large.

\section{A. Balancing of Interests}

When considering non-sports-related injuries, the athlete's interest in keeping his or her PHI private arguably outweighs the interests of the athletic organizations, the media, and the public at large. Injuries unrelated to the participation in the sport do not share the same connectivity to the team's community building efforts and publicly funded stadiums. In addition, such information is more private because of its greater potential for embarrassment or offense, and because the athlete has not thrust that information into the limelight. As a result, such information is not an appropriate public concern and should not be released even with proper authorization.

Using this same balancing test to analyze sports-related injuries, the athlete's interest in keeping his or her PHI private arguably succumbs to the interests of athletic organizations, the media, and the public. Injuries related to the participation in the sport are arguably more connected to an organization's community building efforts and publicly funded stadium. In addition, such information is of more legitimate public concern because of the athlete's choice to thrust themselves into the limelight by playing a collegiate or professional sport. Further, a sport's organization has a vested business interest in keeping its fan base content. Keeping information about a star player from the fans may diminish some of that support. As a result, an organization's interest in running a successful business and the public's interest in staying apprised of an athlete's playing status sufficiently outweighs that athlete's interest in keeping their PHI private.

\section{B. Authorization}

In addition to only releasing information related to the player's participation in a sport, sports organizations should make sure to obtain a HIPAAcompliant authorization form for the release of information from each player. ${ }^{214}$ Each authorization form should include: the identity of the athlete, the PHI authorized for release, the athlete's signature, and the date. ${ }^{215}$ The authorization form should also document the purpose of the release, who can use and distribute the released information, who can receive the released information, and an expiration date or event. ${ }^{216}$ Everything within the authorization form should be stated with specificity to avoid classification as a blanket authorization. $^{217}$ As long as an authorization form includes all of these necessary ele-

214. See Sullivan, supra note 34, at 14.

215. See id.

216. See id.

217. See id. 
ments, it may be a part of the aforementioned standard authorization, the notice plus informed consent authorization, or a collective bargaining agreement.

\section{Public Policy}

The public policy considerations associated with the release of injury information are arguably not strong enough to prevent sports organizations from releasing information related to an athlete's participation in the sport. While the release of injury information may contribute to the formulation of betting lines and contribute to sports betting in general, too many other factors contribute to the practice of gambling to validate a public policy ban on the release of injury information. In addition, while gambling has some undeniable negative effects, it is not devoid of benefits, such as economic benefits to government coffers.

Further, injury information related to participation in the sport is not too personal to contractually waive the release of such information because the injury occurred within the scope of the athlete's participation in the sport. This lends additional legitimacy to the sports organization's interest in running a business and the public's interest in gaining access to information of public concern.

\section{Organizational Education}

Beyond ensuring that an athlete's PHI relating to their participation in the sport be released only with appropriate authorization, an organization should take the time to educate its employees on HIPAA requirements. Individuals who handle the information within the organization should be educated on what information can and cannot be released and what information should be included within the contents of a HIPAA-compliant authorization form. Taking the time to educate these individuals would eliminate much of the confusion associated within HIPAA compliance in the sports industry.

\section{CONCLUSION}

In the end, sports organizations, with appropriate player authorization, should be permitted to release an athlete's sports-related injury information without being liable for a HIPAA violation. Such a conclusion is consistent with public policy and follows a longstanding athletic tradition supported by the balancing of the player's interest in keeping their PHI private, the organization's interest in running a business, and the public's interests in being apprised of information of public concern. 